\title{
Influence of factors unrelated to environmental quality on occupant satisfaction in LEED and non-LEED certified buildings
}

Stefano Schiavon ${ }^{\mathrm{a}}$, Sergio Altomonte $\mathrm{b}^{\mathrm{*}}$

${ }^{\text {a }}$ Center for the Built Environment, University of California, 388 Wurster Hall, Berkeley, CA 94720-1839, USA

${ }^{\mathrm{b}}$ Department of Architecture and Built Environment, University of Nottingham, University Park, Nottingham, NG7 2RD, UK

* Corresponding author: sergio.altomonte@nottingham.ac.uk

Received 13 December 2013; Received in revised form 28 March 2014; Accepted 30 March 2014

\begin{abstract}
Occupant satisfaction in office buildings has been correlated to the indoor environmental quality of workspaces, but can also be influenced by factors distinct from conventional IEQ parameters such as building features, personal characteristics, and work-related variables. A previous study by the authors analyzed occupant satisfaction in LEED and non-LEED certified buildings on a subset of the Center for the Built Environment survey database featuring 21,477 responses from 144 buildings (65 LEED-rated). The data suggested that, when evaluated comprehensively, there is not a practically significant influence of LEED certification on occupant satisfaction. The aim of this paper is to investigate the impact on users' satisfaction in LEED and non-LEED certified buildings of factors unrelated to environmental quality, including consideration of office type, spatial layout, distance from window, building size, gender, age, type of work, time at workspace, and weekly working hours. The results show that such factors statistically significantly influence the difference in occupant satisfaction in LEED and non-LEED certified buildings, but the effect size of such variations is, for most, practically negligible. However, tendencies were found showing that LEED-rated buildings may be more effective in providing higher satisfaction in open spaces rather than in enclosed offices, in small rather than in large buildings, and to occupants having spent less than one year at their workspace rather than to users that have occupied their workplace for longer. The findings suggest that the positive value of LEED certification from the point of view of occupant satisfaction may tend to decrease with time.
\end{abstract}

\section{KEYWORDS}

Leadership in Energy and Environmental Design (LEED), Occupant Satisfaction, Survey, PostOccupancy Evaluation, Indoor Environmental Quality, Non-environmental factors

Schiavon, S., Altomonte, S., 2014. Influence of factors unrelated to environmental quality on occupant satisfaction in LEED and non-LEED certified buildings. Building and Environment. 77, 148-159

\section{HIGHLIGHTS}

- Impact of non-IEQ factors on satisfaction in LEED and non-LEED buildings was tested

- Non-IEQ factors significantly influence the effectiveness of LEED on satisfaction

- Effect size of differences in satisfaction is almost always practically negligible

- Effectiveness of LEED on satisfaction is higher in small buildings and open spaces

- Effectiveness of LEED on satisfaction may tend to decrease with time

\section{INTRODUCTION}

In the contemporary built environment debate, there is general consensus that the wide-spread diffusion of environmental rating tools at a global level (e.g., LEED in the United States, BREEAM in United Kingdom, Green Mark in Singapore, CASBEE in Japan, Green Star in Australia, etc.) has contributed to move the agenda of sustainability to a central role in the design, operation, and maintenance of buildings. However, research needs to be undertaken to investigate if environmental rating tools are effectively contributing to improved users' workplace experience. An effective way to do this is to use occupant surveys [1-5].

In this context, the CBE Occupant Indoor Environmental Quality Survey administered by the Center for the Built Environment, University of California Berkeley, is a proven and effective tool to appraise occupant satisfaction. A general description of the CBE database is reported in [6]. The survey uses a 7-point ordered scale to rate occupant satisfaction with the building, workspace, and 15 parameters of indoor environmental quality (IEQ), ranging from 'very satisfied' (+3) to 'very dissatisfied' $(-3)$, with a neutral midpoint $(0)$.

The core survey collects general information about the characteristics of the building and its users. It is composed of several modules addressing, respectively: building features; background of the occupants; location and description of workspaces; availability of space; office layout; visual privacy; ease of interaction; 
furnishings; colors and textures; thermal comfort; air quality; lighting; acoustic quality; sound privacy; visual privacy; cleanliness and maintenance; and, general comments [7].

A previous study by the authors focused on a subset of the CBE database - featuring 144 buildings of which 65 LEED-rated, and 21,477 individual responses of which 10,129 in LEED buildings - to investigate if LEED buildings lead to a higher, equal, or lower occupant satisfaction than non-LEED certified buildings [1]. Differently from previous analyses of the CBE database, the results showed that occupants of LEED-rated buildings have equal satisfaction with the building overall and with the workspace than users of non-LEED certified buildings. Similarly, the difference in mean satisfaction scores between LEED and non-LEED buildings for the other 15 IEQ parameters investigated was always lower than $6 \%$, with a negligible effect size. Therefore, it was concluded that there is not a practically significant influence of LEED certification on occupant satisfaction with the building, the workspace, and indoor environmental quality.

Various studies on occupant satisfaction, and its relationship with green rating/LEED certification, have originated from examination of the data featured in the CBE database [8-14]. In these, the satisfaction of occupants in office buildings and their self-reported job performance have been directly correlated to the parameters characterizing the indoor environmental quality of workplaces. An extensive review of research on the correlation between users' IEQ satisfaction, measurable physical parameters of the workplace, and the use of green rating tools such as LEED, is reported in [1]. Further studies also suggest that comfort and satisfaction can be influenced by other variables that designers, building owners, and facilities managers should take into consideration in the design and operation of commercial office spaces [15-19].

In particular, a review of the "factors, unrelated to environmental quality, that influence whether indoor environments are considered to be comfortable or not" has been conducted in a literature survey reported in [20]. The review aimed to investigate if thermal, visual, acoustic, and olfactory factors contribute equally to comfort, and how personal characteristics of the occupants (e.g., gender, age, etc.) and features of the workplace (e.g., room decoration, type of building, control over the indoor environment, etc.) can influence satisfaction. The results indicated that occupants' and buildings' related variables should be taken into account to provide comfortable conditions for users and enhance satisfaction with indoor environmental quality. However, the reviewed studies were generally not consistent with regards to the impact of individual "non-environmental" factors on comfort and satisfaction, also due to differences in their design strength [20].

From these investigations, it can be inferred that non-environmental factors may effectively play an influential role on occupant satisfaction with the building, workspace, and parameters of indoor environmental quality. What is not known, however, is whether such variables may have a different impact on the satisfaction of building users in green-rated rather than in 'conventional' buildings.

In this paper, we analyze the influence of the following non-environmental factors on the satisfaction of occupants in LEED and non-LEED certified buildings: 1) buildings and workspaces features: office type (enclosed, open space), spatial layout (private offices, shared offices, cubicles with high, low or no partitions), distance of workstations from windows, building size; 2) occupants' personal characteristics: gender, age; 3) work-related variables: type of work, time at the current workspace, weekly working hours.

Results of this analysis may lead to identify the potential different role that design strategies and solutions aimed towards the attainment of LEED certification can have on the satisfaction - and possibly the perceived feeling of health, well-being, and job performance - of occupants at their place of work, therefore influencing the decision making process in the design, operation, and maintenance of commercial office buildings and, ultimately, informing the development of the LEED program itself.

\section{METHODS}

\subsection{Description of the dataset}

The dataset for the analysis presented in this paper is based on the same subset of the CBE Occupant Indoor Environmental Quality Survey database described in a previous study by the authors [1]. The dataset features 21,477 individual responses obtained from 144 buildings, of which 65 have been LEED-rated $(10,129$ responses) and 79 have not been certified by LEED (11,348 responses). The methods for the selection of the buildings to be included in the LEED and non-LEED groups are described in detail in [1].

Responses were gathered from occupants of office buildings - mainly governmental, offices occupied by private companies, universities and research centers - fitted with workstations of varied layouts, coherently with the eligibility criteria presented in [13]. The 65 buildings included in the LEED group have received a certification under LEED for New Constructions (LEED NC), LEED for Commercial Interiors (LEED CI), or LEED for Existing Buildings (LEED EB). The detailed distribution of responses of occupants according to LEED product (NC, CI, or EB), level of certification (Platinum, Gold, Silver, Certified), and version of the rating tool $(1,2.0,2.1,2.2)$ is reported in Table 4 of [1].

The two groups - LEED and non-LEED - are homogeneous in terms of the number of buildings and individual occupants' responses featured in each, their year of construction and/or renovation, and also as regards with their size, as shown in the summary statistics presented in Table 3 of [1]. 
Table 1. Distribution of occupants' responses based on non-environmental factors

\begin{tabular}{|c|c|c|c|c|}
\hline \multirow{2}{*}{$\begin{array}{l}\text { Non-environmental Factors } \\
\text { Office Type }\end{array}$} & \multicolumn{4}{|c|}{ Number of Occupants' Responses } \\
\hline & LEED & non-LEED & Total & Not Available \\
\hline Enclosed & $2,078(21 \%)$ & $3,048(27 \%)$ & $5,126(24 \%)$ & \\
\hline Open Space & $8,051(79 \%)$ & $8,300(73 \%)$ & $16,351(76 \%)$ & \\
\hline Total & 10,129 & 11,348 & 21,477 & $\mathbf{0}$ \\
\hline Spatial Layout & LEED & non-LEED & Total & Not Available \\
\hline Private Office & $1,738(17 \%)$ & $2,413(21 \%)$ & $4,151(19 \%)$ & \\
\hline Shared Office & $340(3 \%)$ & $635(6 \%)$ & $975(5 \%)$ & \\
\hline Cubicles with high partitions ${ }^{\mathrm{a}}$ & $5,177(51 \%)$ & $4,285(38 \%)$ & $9,462(44 \%)$ & \\
\hline Cubicles with low partitions & $2,425(24 \%)$ & $3,043(27 \%)$ & $5,468(25 \%)$ & \\
\hline Other $^{\mathrm{b}}$ & $449(4 \%)$ & $972(9 \%)$ & $1,421(7 \%)$ & \\
\hline Total & 10,129 & 11,348 & 21,477 & $\mathbf{0}$ \\
\hline Distance from Window & LEED & non-LEED & Total & Not Available \\
\hline Within 4.6 meters ( 15 feet) & $6,661(66 \%)$ & $7,671(69 \%)$ & $14,332(67 \%)$ & \\
\hline Further than 4.6 meters ( 15 feet) & $3,427(34 \%)$ & $3,491(31 \%)$ & $6,918(33 \%)$ & \\
\hline Total & 10,088 & 11,162 & 21,250 & $227(1 \%)$ \\
\hline Building Size & LEED & non-LEED & Total & Not Available \\
\hline Small (less than $4,645 \mathrm{~m}^{2}$ or 50,000 gsf) & $1,150(16 \%)$ & $634(6 \%)$ & $1,784(11 \%)$ & \\
\hline Medium (between 4,645 and $\left.18,580 \mathrm{~m}^{2}\right)^{\mathrm{c}}$ & $1,733(24 \%)$ & $2,882(30 \%)$ & $4,615(27 \%)$ & \\
\hline Large (higher than $18,580 \mathrm{~m}^{2}$ or $200,000 \mathrm{gsf}$ ) & $4,283(60 \%)$ & $6,240(64 \%)$ & $10,523(62 \%)$ & \\
\hline Total & 7,166 & 9,756 & 16,922 & $4,555(21 \%)$ \\
\hline Gender & LEED & non-LEED & Total & Not Available \\
\hline Female & $2,517(56 \%)$ & $6,206(57 \%)$ & $8,723(57 \%)$ & \\
\hline Male & $2,011(44 \%)$ & $4,645(43 \%)$ & $6,656(43 \%)$ & \\
\hline Total & 4,528 & 10,851 & 15,379 & $6,098(28 \%)$ \\
\hline Age & LEED & non-LEED & Total & Not Available \\
\hline 30 or under & $929(21 \%)$ & $1,019(17 \%)$ & $1,948(19 \%)$ & \\
\hline $31-50$ & $2,326(51 \%)$ & $3,145(54 \%)$ & $5,471(53 \%)$ & \\
\hline Over 50 & $1,264(28 \%)$ & $1,669(29 \%)$ & $2,933(28 \%)$ & \\
\hline Total & 4,519 & 5,833 & 10,352 & $11,125(52 \%)$ \\
\hline Type of Work & LEED & non-LEED & Total & Not Available \\
\hline Administrative & $829(18 \%)$ & $568(22 \%)$ & $1,397(19 \%)$ & \\
\hline Technical & $889(19 \%)$ & $468(18 \%)$ & $1,357(19 \%)$ & \\
\hline Professional & $2,024(43 \%)$ & $973(37 \%)$ & $2,997(41 \%)$ & \\
\hline Managerial/Supervisory & $641(14 \%)$ & $437(17 \%)$ & $1,078(15 \%)$ & \\
\hline Other & $339(7 \%)$ & $155(6 \%)$ & $494(7 \%)$ & \\
\hline Total & 4,722 & 2,601 & 7,323 & $14,154(66 \%)$ \\
\hline Time at Workspace & LEED & non-LEED & Total & Not Available \\
\hline Less than 1 year & $1,204(33 \%)$ & $660(31 \%)$ & $1,864(33 \%)$ & \\
\hline More than 1 year & $2,410(67 \%)$ & $1,449(69 \%)$ & $3,859(67 \%)$ & \\
\hline Total & 3,614 & 2,109 & 5,723 & $15,754(73 \%)$ \\
\hline Weekly Working Hours & LEED & non-LEED & Total & Not Available \\
\hline 10 or less & $272(3 \%)$ & $403(4 \%)$ & $675(4 \%)$ & \\
\hline $11-30$ & $1,406(18 \%)$ & $1,954(18 \%)$ & $3,360(18 \%)$ & \\
\hline More than 30 & $6,106(78 \%)$ & $8,274(78 \%)$ & $14,380(78 \%)$ & \\
\hline Total & 7,784 & 10,631 & 18,415 & $3,062(14 \%)$ \\
\hline
\end{tabular}

${ }^{\text {a Partitions higher than } 1.5 \text { meters }}$

${ }^{\mathrm{b}}$ The Other category includes open layouts such as: workspace in open office with two partitions; cubicles with partitions of different heights; group work area; open plan with limited partitions; open workspace with no partitions

${ }^{\mathrm{c}}$ Building size between 50,000 and 200,000 gsf 
To note that the criteria for the selection of the dataset described in [1] do not exclude that non-LEED buildings may have received some other certification by an alternative rating system, have been certified by LEED in the years following the administration of the CBE survey, or have some or several 'green' credentials. This possibility is, however, beyond the scope of the analysis presented in this paper that uniquely aims to examine the relationship between LEED certification and occupant satisfaction based on consideration of nonenvironmental factors.

For the purpose of the study described in this paper, it is also important that the two groups of buildings are comparable in terms of distribution of occupants' responses according to: office type; spatial layout; distance from window; building size; gender; age; type of work; time at workspace; and, weekly working hours. Table 1 illustrates such comparison, highlighting that both the LEED and non-LEED groups feature mostly open office layouts $(79 \%$ of responses in LEED and $73 \%$ in non-LEED buildings) and primarily with workspaces at a distance within 4.6 meters (15 feet) from the window (66\% of occupants in LEED and 69\% in non-LEED buildings). In terms of building size, both LEED and non-LEED buildings have predominantly (60\% of responses in LEED and 64\% in non-LEED buildings) a gross area larger than $18,580 \mathrm{~m}^{2}$ (200,000 gsf). Comparable distributions of responses between LEED and non-LEED buildings can be observed for buildings of small and medium size. Both groups of buildings have a workforce with a slightly higher percentage of women (56\% in LEED and 57\% in non-LEED buildings) and within the age group between 31 and 50 years $(51 \%$ of occupants in LEED and 54\% in non-LEED buildings). The distribution of occupants' responses according to type of work, time at the workspace, and weekly working hours is also consistent between LEED and non-LEED buildings. However, in the present study, with respect to the dataset previously analyzed by the authors and presented in Table 5 of [1], the categorizations of time at the workspace featuring responses of occupants having spent at their current place of work between '4-6 months' and '7-12 months' have been consolidated under the single category 'Less than 1 year', since the category '4-6 months' had a small sample size.

Finally, Table 1 indicates the number of 'not available' responses under each variable considered, and their percentage with respect to the total individual responses included in the dataset $(21,477)$. The percentage of 'not available' responses denotes where occupants have not provided specific information regarding the various non-environmental factors taken into consideration by this analysis.

For the purpose of this study, the CBE survey modules have been organized based on occupant satisfaction with the following order of parameters: 1) building; 2) workspace; 3 ) ease of interaction; 4) building cleanliness; 5) comfort of furnishing; 6) amount of light; 7) building maintenance; 8) colors and textures; 9) workspace cleanliness; 10) amount of space; 11) furniture adjustability; 12) visual comfort; 13) air quality; 14) visual privacy; 15) noise; 16) temperature; 17) sound privacy.

This order has been established according to the findings presented in [1] and, with the exception of satisfaction with the building and with the workspace, it follows a sequence of decreasing occupant satisfaction calculated over the entire available dataset (that is, indistinctively considering all responses obtained in both LEED and non-LEED certified buildings).

\subsection{Statistical methods}

The mean (M) and median values of satisfaction with the building, workspace, and 15 parameters of indoor environmental quality were calculated by averaging individual satisfaction votes of occupants in the whole dataset in LEED and non-LEED buildings for each of the nine non-environmental factors considered.

The statistical significance of the differences in mean votes of satisfaction ( $\triangle \mathrm{M}$, LEED minus non-LEED) with the building, workspace and IEQ parameters for each non-environmental factor was tested with the Wilcoxon rank sum test since the variables had an ordinal character [21].

For all tests, the results were considered statistically significant when $\mathrm{p}<0.05$ (that is, the probability that a difference could have arisen by chance was below 5\%). To mitigate the risk that statistical tests had led to significant p-values by an accident of sampling - which could arise particularly when performing a large number of statistical tests - and to quantify the relevance of statistically significant differences, the power analysis was performed and the effect size index was calculated for each statistical influence tested [22].

There are indeed several limitations with using null hypothesis significance testing (NHST) as a way of inferring the size (or relative impact) of the difference between two sample groups [23, 24]. The main one is that the p-value depends both on the size of the effect and on the size of the sample. So, a test may result statistically significant if either the effect were very big, or if the sample were very large. Conversely, by placing the emphasis on the most important aspect of the analysis - that is, the size of the effect (i.e., the standardized, scalefree, mean difference) and not just its statistical significance (which effectively confounds effect size and sample size) - the effect size index shows if the predictor variable has any practical significance and thus provides a more rigorous support to inferences and conclusions $[25,26]$.

In the study, the Spearman rank correlation (Rho, $\rho$ ) was used to estimate the standardized size of the mean difference in IEQ satisfaction between the two groups considered (LEED and non-LEED certified), hence representing a more reliable measure of its relevance. Effect sizes have been calculated by making use of 
equivalence between the standardized mean difference and the Spearman rank correlation coefficient since data were categorical and non-normally distributed [27, 28]. The 'group membership' for the correlation has been coded with a hidden dummy variable (i.e., denoting the LEED group by 0 and the non-LEED group by 1 ) and the correlation between this variable and the outcome measure (that is, the satisfaction with a given IEQ parameter based on various categorizations of non-environmental factors) was calculated. The interpretation of the outcome was derived from the tables provided in [26], where conventional values have been proposed as benchmarks for 'small' (RMPE, recommended minimum effect size representing a practically significant effect), 'moderate', and 'strong' effects sizes ( $\rho \geq 0.20,0.50$, and 0.80 , respectively); $\rho$ values lower than 0.20 can be considered negligible.

The statistical analysis was carried out with R software 2.15.1 [29].

\section{RESULTS}

Table 2 presents the difference in mean vote of satisfaction ( $\triangle \mathrm{M}$, LEED minus non-LEED) with the building, workspace, and 15 IEQ parameters for each of the non-environmental factors considered and their categorizations. A positive $\Delta \mathrm{M}$ denotes a higher mean vote of satisfaction given by occupants of LEED buildings and, on the contrary, negative $\Delta \mathrm{M}$ values signal a higher satisfaction for users of buildings not certified by LEED. In Table 2, values marked in bold italic indicate a difference $\triangle \mathrm{M}$ in mean satisfaction in LEED and nonLEED buildings either equal or higher than +0.40 , or equal or lower than -0.40 . The values of +0.40 and -0.40 were chosen since - based on the results obtained by the authors in [1], and reported in the second row of Table 2 - they represent the largest overall variation (i.e., irrespective of consideration of non-environmental factors) in mean vote of satisfaction between LEED and non-LEED buildings upon analysis of the entire sample of occupants' responses (maximum overall difference in mean votes of $\Delta \mathrm{M}=+0.40$ for satisfaction with air quality, and of $\Delta \mathrm{M}=-0.40$ for satisfaction with amount of light). The third column of Table 2 provides the number of individual responses in each categorization of the nine non-environmental factors considered.

The data of Table 2 can highlight potential trends of influence of non-environmental factors on the variation of occupant satisfaction in LEED and non-LEED buildings. For example, a clear trend of improvement of efficacy of LEED certification in terms of satisfaction with the building and with the workspace can be recognized when moving from private offices (respectively $\Delta \mathrm{M}=-0.12$ for satisfaction with building and $\Delta \mathrm{M}=-$ 0.18 for satisfaction with the workspace; that is, higher occupant satisfaction in non-LEED buildings), to shared offices $(\Delta \mathrm{M}=-0.19$ and $\Delta \mathrm{M}=-0.05)$, to cubicle with high partitions $(\Delta \mathrm{M}=+0.00$ and $\Delta \mathrm{M}=+0.09)$, to cubicle with low partitions $(\Delta \mathrm{M}=+0.22$ and $\Delta \mathrm{M}=+0.34)$, and finally to 'other' open layouts $(\Delta \mathrm{M}=+0.49$ and $\Delta \mathrm{M}=$ +0.68 ; that is, users more satisfied with the building and the workspace in LEED buildings). Similar trends are also recognizable for satisfaction with other IEQ parameters such as noise, temperature, and sound privacy.

Table 3 presents the effect size (Spearman Rho, $\rho$ ) and the statistical significance of the difference in mean vote of satisfaction $(\Delta \mathrm{M})$ with the building, workspace, and 15 IEQ parameters for each nonenvironmental factor considered and their categorizations. The second row of Table 3 reports the effect size and the statistical significance of the differences in mean vote of satisfaction with all the parameters analyzed in LEED and non-LEED buildings calculated on the entire sample of 21,477 responses, i.e. without taking into account potential influence of non-environmental factors, as presented in [1].

In Table 3, values marked in bold italic indicate a 'small' effect size $(0.20 \leq \rho<0.50)$. None of the effect size values calculated for the correlations considered in this study was equal or higher than 0.50 , and therefore it can be concluded there were not 'moderate' nor 'strong' effect sizes. As an example, the above mentioned differences in mean vote of satisfaction with building, workspace, noise, temperature, and sound privacy expressed by occupants of LEED and non-LEED buildings in different spatial layouts are statistically significant $(p<0.05)$ in most cases (19 out of 25$)$, but their effect size is not negligible $(\rho \geq 0.20)$ only for satisfaction with the workspace in 'other' open offices $(\rho=0.22)$.

Table 4 presents the absolute variation $(\Delta \mathrm{V}$, always positive $)$ - i.e. the 'spread' of the differences - of the mean vote of satisfaction ( $\Delta \mathrm{M}$, reported in Table 2$)$ with the building, workspace, and 15 IEQ parameters given by occupants of LEED and non-LEED buildings for each non-environmental factor evaluated by this study. In Table 4, values marked in bold italic indicate an absolute variation of mean vote of satisfaction $\Delta \mathrm{V}$ equal or higher than 0.40 . As mentioned, the value of 0.40 was chosen since, based on the results illustrated in [1], it represents the largest overall variation of mean vote of occupant satisfaction between LEED and non-LEED buildings irrespective of analysis of non-environmental factors.

For example, the absolute 'spread' of occupant satisfaction with amount of light between LEED and nonLEED buildings based on consideration of the size of the building is $\Delta V=1.10$, resulting as the 'range' between a higher mean vote of occupant satisfaction with amount of light in non-LEED buildings of large size $(\triangle \mathrm{M}=$ 0.73 , as per Table 2), and occupants more satisfied with this parameter of indoor environmental quality in LEED buildings of small size $(\Delta \mathrm{M}=+0.37)$. 
Table 2. Difference in mean vote of satisfaction ( $\triangle \mathrm{M}$, LEED minus non-LEED) with building, workspace and 15 IEQ parameters for each non-environmental factor and their categorizations

\begin{tabular}{|c|c|c|c|c|c|c|c|c|c|c|c|c|c|c|c|c|c|c|c|}
\hline & & & 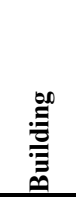 & 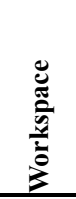 & 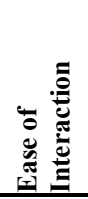 & 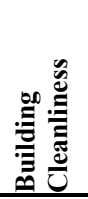 & 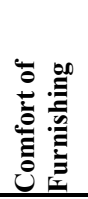 & 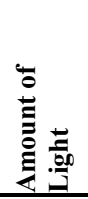 & 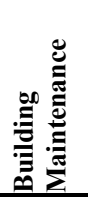 & 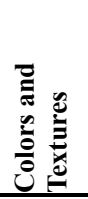 & 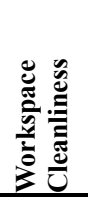 & 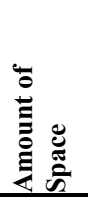 & 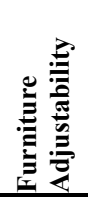 & 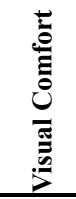 & 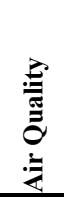 & 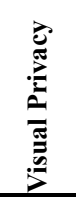 & $\frac{\ddot{n}}{\ddot{g}}$ & 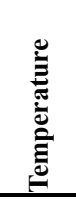 & 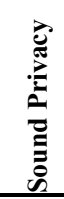 \\
\hline Overall Difference I & LEED - non-LEED & $N=21,477$ & 0.01 & 0.08 & -0.22 & 0.13 & -0.01 & -0.40 & 0.23 & 0.17 & 0.13 & -0.11 & 0.01 & -0.16 & 0.40 & -0.17 & -0.10 & -0.01 & -0.08 \\
\hline \multirow{2}{*}{ Office Type } & Enclosed & $\mathrm{N}=5,126$ & -0.12 & -0.14 & -0.36 & 0.20 & -0.09 & -0.28 & 0.27 & 0.02 & 0.16 & 0.00 & -0.07 & -0.15 & 0.34 & -0.37 & -0.27 & -0.35 & -0.20 \\
\hline & Open & $\mathrm{N}=16,351$ & 0.09 & 0.21 & -0.14 & 0.13 & 0.05 & -0.39 & 0.23 & 0.23 & 0.14 & -0.07 & 0.06 & -0.13 & 0.46 & 0.02 & 0.06 & 0.15 & 0.12 \\
\hline \multirow{5}{*}{ Spatial Layout } & Private Office & $\mathrm{N}=4,151$ & -0.12 & -0.18 & -0.39 & 0.20 & -0.06 & $\begin{array}{c}-0.32 \\
\end{array}$ & 0.31 & 0.03 & 0.18 & -0.05 & -0.04 & -0.17 & 0.34 & -0.56 & -0.30 & -0.38 & -0.31 \\
\hline & Shared Office & $\mathrm{N}=975$ & -0.19 & -0.05 & -0.27 & 0.15 & -0.32 & -0.16 & 0.07 & -0.14 & 0.11 & 0.01 & -0.30 & -0.09 & 0.23 & 0.16 & -0.26 & -0.27 & 0.01 \\
\hline & Cubicles high partitions & $\mathrm{N}=9,462$ & 0.00 & 0.09 & -0.20 & -0.03 & -0.01 & -0.59 & 0.09 & 0.20 & -0.04 & -0.31 & 0.03 & -0.24 & 0.50 & -0.22 & -0.06 & 0.12 & 0.04 \\
\hline & Cubicles low partitions & $\mathrm{N}=5,468$ & 0.22 & 0.34 & 0.01 & 0.35 & 0.15 & -0.12 & 0.44 & 0.30 & 0.38 & 0.22 & 0.15 & 0.04 & 0.48 & 0.15 & 0.19 & 0.21 & 0.28 \\
\hline & Other & $\mathrm{N}=1,421$ & 0.49 & 0.68 & -0.03 & 0.47 & 0.22 & 0.38 & 0.58 & 0.34 & 0.57 & 0.50 & 0.24 & 0.20 & 0.56 & 0.59 & 0.64 & 0.22 & 0.56 \\
\hline \multirow{2}{*}{$\begin{array}{c}\text { Distance from } \\
\text { Window } \\
\end{array}$} & Further than $4.6 \mathrm{~m}(15 \mathrm{ft})$ & $\mathrm{N}=14,332$ & 0.01 & 0.10 & -0.23 & 0.03 & 0.02 & -0.39 & 0.13 & 0.21 & 0.02 & -0.15 & 0.04 & -0.14 & 0.47 & -0.10 & -0.04 & 0.07 & 0.11 \\
\hline & Within $4.6 \mathrm{~m}(15 \mathrm{ft})$ & $\mathrm{N}=6,918$ & 0.02 & 0.09 & -0.20 & 0.18 & -0.01 & -0.39 & 0.27 & 0.15 & 0.18 & -0.08 & 0.00 & -0.17 & 0.37 & -0.17 & -0.11 & -0.04 & -0.15 \\
\hline \multirow{3}{*}{ Building size } & Small & $\mathrm{N}=1,784$ & 0.33 & 0.25 & -0.02 & 0.43 & 0.02 & 0.37 & 0.50 & 0.23 & 0.24 & 0.17 & 0.19 & 0.33 & 0.42 & -0.46 & -0.30 & 0.00 & -0.36 \\
\hline & Medium & $\mathrm{N}=4,615$ & 0.10 & 0.23 & -0.01 & 0.20 & 0.11 & -0.14 & 0.11 & 0.24 & 0.25 & 0.28 & 0.13 & -0.01 & 0.43 & 0.01 & 0.31 & -0.01 & 0.43 \\
\hline & Large & $\mathrm{N}=10,523$ & 0.02 & -0.05 & -0.49 & 0.20 & 0.01 & -0.73 & 0.36 & 0.29 & 0.19 & -0.35 & 0.05 & -0.30 & 0.53 & -0.18 & -0.28 & 0.20 & -0.17 \\
\hline \multirow{2}{*}{ Gender } & Female & $\mathrm{N}=8,723$ & 0.28 & 0.38 & 0.08 & 0.36 & 0.21 & 0.01 & 0.47 & 0.28 & 0.41 & 0.38 & 0.23 & 0.15 & 0.73 & 0.20 & 0.30 & 0.15 & 0.46 \\
\hline & Male & $\mathrm{N}=6,656$ & 0.29 & 0.46 & 0.05 & 0.41 & 0.29 & 0.09 & 0.42 & 0.36 & 0.45 & 0.36 & 0.32 & 0.19 & 0.63 & 0.26 & 0.32 & 0.33 & 0.47 \\
\hline \multirow{3}{*}{ Age } & 30 or Under & $\mathrm{N}=1,948$ & 0.21 & 0.30 & -0.10 & 0.47 & 0.23 & 0.17 & 0.55 & 0.25 & 0.60 & 0.27 & 0.20 & 0.16 & 0.41 & 0.23 & 0.14 & 0.19 & 0.35 \\
\hline & $31-50$ & $\mathrm{~N}=5,471$ & 0.25 & 0.34 & 0.02 & 0.36 & 0.06 & 0.10 & 0.44 & 0.18 & 0.45 & 0.26 & 0.07 & 0.13 & 0.43 & 0.24 & 0.33 & 0.16 & 0.43 \\
\hline & Over 50 & $\mathrm{~N}=2,933$ & 0.22 & 0.27 & -0.12 & 0.42 & 0.16 & -0.08 & 0.42 & 0.23 & 0.42 & 0.36 & 0.11 & 0.08 & 0.55 & 0.24 & 0.24 & 0.24 & 0.39 \\
\hline \multirow{5}{*}{ Type of Work } & Administrative & $\mathrm{N}=1,397$ & -0.03 & $\begin{array}{l}-0.03 \\
\end{array}$ & -0.25 & 0.36 & -0.07 & -0.26 & 0.38 & -0.18 & 0.40 & -0.12 & 0.01 & -0.09 & 0.00 & 0.01 & -0.32 & -0.08 & -0.17 \\
\hline & Technical & $\mathrm{N}=1,357$ & 0.41 & 0.38 & -0.28 & 0.95 & 0.08 & 0.10 & 1.01 & 0.26 & 0.93 & -0.07 & 0.16 & 0.03 & 0.34 & 0.24 & 0.25 & 0.20 & -0.04 \\
\hline & Professional & $\mathrm{N}=2,997$ & 0.33 & 0.31 & -0.18 & 0.89 & 0.16 & -0.19 & 1.02 & 0.32 & 0.83 & 0.33 & 0.16 & -0.06 & 0.35 & 0.28 & 0.18 & 0.34 & 0.13 \\
\hline & Managerial/Supervision & $\mathrm{N}=1,078$ & 0.24 & 0.20 & -0.23 & 0.71 & 0.01 & -0.15 & 0.86 & 0.11 & 0.85 & 0.25 & -0.21 & -0.24 & 0.28 & -0.23 & -0.25 & 0.14 & -0.12 \\
\hline & Other & $\mathrm{N}=494$ & 0.33 & 0.42 & -0.33 & 1.03 & 0.21 & 0.25 & 1.15 & 0.27 & 1.07 & 0.34 & 0.44 & 0.09 & 0.61 & 0.36 & 0.25 & 0.24 & 0.41 \\
\hline \multirow{2}{*}{$\begin{array}{c}\text { Time at } \\
\text { Workspace }\end{array}$} & Less than 1 year & $\mathrm{N}=1,864$ & 0.59 & 0.63 & -0.14 & 0.82 & 0.34 & 0.01 & 0.97 & 0.36 & 0.84 & 0.71 & 0.30 & 0.14 & 0.57 & 0.99 & 0.56 & 0.49 & 0.74 \\
\hline & More than 1 year & $\mathrm{N}=3,859$ & 0.12 & 0.05 & -0.24 & 0.85 & -0.05 & -0.25 & 0.92 & 0.06 & 0.80 & -0.02 & -0.02 & -0.19 & 0.18 & -0.26 & -0.27 & 0.08 & -0.31 \\
\hline \multirow{3}{*}{$\begin{array}{c}\text { Weekly Working } \\
\text { Hours }\end{array}$} & 10 or less & $\mathrm{N}=675$ & 0.27 & 0.47 & -0.07 & 0.26 & 0.22 & 0.03 & 0.30 & 0.41 & 0.32 & 0.23 & 0.26 & 0.27 & 0.80 & 0.22 & 0.06 & 0.35 & 0.24 \\
\hline & $11-30$ & $\mathrm{~N}=3,360$ & 0.11 & 0.18 & -0.13 & 0.23 & 0.12 & -0.23 & 0.26 & 0.28 & 0.30 & 0.06 & 0.12 & 0.01 & 0.51 & -0.05 & 0.13 & 0.12 & 0.09 \\
\hline & More than 30 & $\mathrm{~N}=14,380$ & 0.01 & 0.02 & -0.28 & 0.09 & -0.01 & -0.49 & 0.21 & 0.20 & 0.07 & -0.14 & 0.02 & -0.20 & 0.45 & -0.18 & -0.15 & 0.06 & -0.07 \\
\hline
\end{tabular}

$\mathrm{N}=$ number of responses

A positive $\triangle \mathrm{M}$ indicates a higher mean vote of satisfaction in LEED buildings

Values in bold italic indicate a difference in mean vote of satisfaction $(\Delta \mathrm{M})$ higher than 0.40 or lower than -0.40 


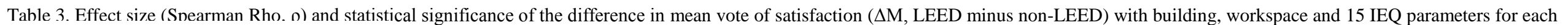
non-environmental factor and their categorizations

\begin{tabular}{|c|c|c|c|c|c|c|c|c|c|c|c|c|c|c|c|c|c|c|c|}
\hline & & & 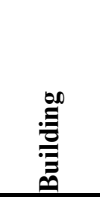 & 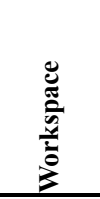 & 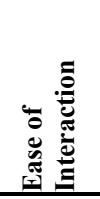 & 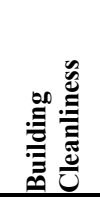 & 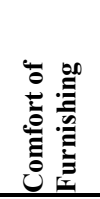 & 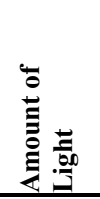 & 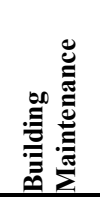 & 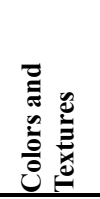 & 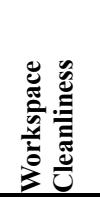 & 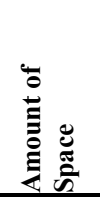 & 总 & 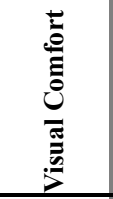 & 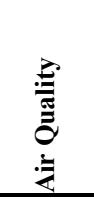 & 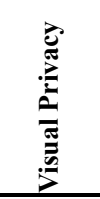 & $\stackrel{\ddot{m}}{\ddot{a}}$ & 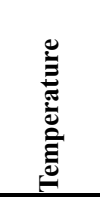 & 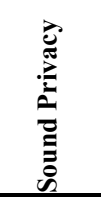 \\
\hline erall D & LEED - non-LEED & $\mathrm{N}=21,477$ & $.02 * * *$ & $.03 * * *$ & $-0.07 * * *$ & $0.07^{* * *}$ & $0.00 \mathrm{n} . \mathrm{s}$. & $-0.09 * * *$ & $0.09 * * *$ & $0.06 * * *$ & $0.05^{* * *}$ & $-0.02 * *$ & $0.01 \mathrm{n} . \mathrm{s}$. & $-0.04 * * *$ & $12 * * *$ & $-0.04 * * *$ & $-0.03 * * *$ & $.00 \mathrm{n} . \mathrm{s}$. & $-0.02 * *$ \\
\hline \multirow{2}{*}{ ffice Type } & Enclosed & $\mathrm{N}=5,126$ & .01 n.s. & $-0.04 * *$ & $-0.11^{* * *}$ & $11^{* * *}$ & 02 n.s. & $-0.07 * * *$ & $0.12 * * *$ & 02n.s. & $.07 * * *$ & 0.00 n.s. & -0.01 n.s. & $-0.03 *$ & $.11 * * *$ & $-0.10^{* * *}$ & $-0.08^{* * *}$ & $0.09 * * *$ & $-0.05^{* * *}$ \\
\hline & Open & $\mathrm{N}=16,351$ & $0.05 * * *$ & $0.07 * * *$ & $-0.04 * * *$ & $0.06^{* * *}$ & $0.02 * *$ & $-0.09 * * *$ & $0.09 * * *$ & $0.08^{* * *}$ & $0.05^{* * *}$ & -0.01 n.s. & $0.02 * *$ & $-0.03 * * *$ & $0.14 * * *$ & 0.01 n.s. & $0.02 *$ & $0.04 * * *$ & $0.03^{* * *}$ \\
\hline \multirow{5}{*}{ Spatial Layout } & Private & $\mathrm{N}=4,15$ & -0.01 n.s. & $-0.05^{* * *}$ & $-0.12 * * *$ & $0.12^{* * *}$ & $-0.01 \mathrm{n} . \mathrm{s}$ & $-0.09 * * *$ & $0.13 * * *$ & 0.03 n.s. & $0.07 * * *$ & -0.01 n.s. & $0.00 \mathrm{n} . \mathrm{s}$ & $-0.04 *$ & $0.12^{* * *}$ & $-0.15^{* * *}$ & $-0.08 * * *$ & $-0.10^{* * *}$ & $-0.08 * * *$ \\
\hline & Shared Office & $\mathrm{N}=975$ & -0.05 n.s. & -0.02 n.s. & $-0.08^{*}$ & $0.07 *$ & $-0.10^{* *}$ & $-0.03 n . s$. & 0.05 n.s. & -0.04 n.s. & 0.04 n.s. & 0.00n.s. & $-0.09 * *$ & -0.02 n.s. & $0.08^{*}$ & 0.04 n.s. & $-0.08 *$ & $-0.07 *$ & 0.00n.s. \\
\hline & Cubicles high partitions & $\mathrm{N}=9,462$ & $0.02 *$ & $0.03 * *$ & $-0.06^{* * *}$ & 0.01 n.s. & $0.00 \mathrm{n} . \mathrm{s}$ & $-0.15^{* * *}$ & $0.04 * * *$ & $0.07^{* * * *}$ & $0.00 \mathrm{n} . \mathrm{s}$ & $-0.08 * * *$ & 0.01 n.s. & $-0.06 * * *$ & $0.15^{* * * *}$ & $-0.06^{* * *}$ & -0.02 n.s. & $0.03 * *$ & 0.00 n.s. \\
\hline & Cubicles & $\mathrm{N}=5,468$ & $0.09 * * *$ & $0.12^{* * *}$ & 0.01 n.s. & $14^{* * * *}$ & $0.06^{* * *}$ & 0.00 n.s. & $0.16^{* * *}$ & $.11^{* * *}$ & $0.13^{* * *}$ & $0.07 * * *$ & $0.05^{* * *}$ & $0.03 *$ & $0.15^{* * *}$ & $0.04 * *$ & $0.05^{* * *}$ & $0.06^{* * *}$ & $0.08^{* * * *}$ \\
\hline & Other & $\mathrm{N}=1,421$ & $0.18 * * *$ & $0.22 * * *$ & 0.01 n.s. & $0.15^{* * * *}$ & $0.08 * *$ & $0.14 * * *$ & $0.18 * * *$ & $0.12 * * *$ & $0.15^{* * *}$ & $0.13 * * *$ & $0.09 * *$ & $0.08 * *$ & $0.17 * * *$ & $0.14 * * *$ & $0.17 * * *$ & $0.05^{*}$ & $0.14 * * *$ \\
\hline \multirow{2}{*}{$\begin{array}{c}\text { Distance from } \\
\text { Window } \\
\end{array}$} & Further & $\mathrm{N}=14,332$ & $0.03^{*}$ & $0.04 * *$ & $-0.07 * * *$ & $0.03 *$ & 0.01 n.s. & $-0.09 * * *$ & $0.06 * * *$ & $0.07 * * *$ & $0.02 \mathrm{n} . \mathrm{s}$ & $-0.04 * *$ & 0.02 n.s. & $-0.03 * *$ & $0.14 * * *$ & $-0.02 *$ & -0.01 n.s. & 0.02 n.s. & $0.03 *$ \\
\hline & Within 4.6 & $\mathrm{~N}=6,918$ & $0.03^{* * * *}$ & $0.03 * * *$ & $-0.06^{* * * *}$ & $0.09^{* * *}$ & 0.00n.s. & $-0.09^{* * * *}$ & $0.11^{* * *}$ & $0.06^{* * * *}$ & $0.07^{* * * *}$ & $-0.01 \mathrm{n} . \mathrm{s}$. & $0.01 \mathrm{n} . \mathrm{s}$. & $-0.04 * * *$ & $0.11^{* * *}$ & $-0.05^{* * * *}$ & $-0.03 * * *$ & $-0.01 \mathrm{n} . \mathrm{s}$. & $-0.04 * * *$ \\
\hline \multirow{3}{*}{ Building size } & Small & $\mathrm{N}=1,784$ & $3 * * *$ & $0.09 * * *$ & $0.00 \mathrm{n} . \mathrm{s}$. & $0.15^{* * * *}$ & 0.02 n.s. & $0.13 * * *$ & $0.17 * * *$ & $0.08^{* * *}$ & $0.07 * *$ & 0.05 n.s. & $0.06^{* *}$ & $0.10^{* * *}$ & $0.13 * * *$ & $-0.12 * * *$ & $-0.08^{* * *}$ & $0.00 \mathrm{n} . \mathrm{s}$. & $-0.09 * * *$ \\
\hline & Medium & $\mathrm{N}=4,615$ & $0.06 * * *$ & $0.08 * * *$ & 0.00 n.s. & $10^{* * * *}$ & $0.04 * *$ & -0.02 n.s. & $0.07 * * *$ & $0.09 * * *$ & $0.10^{* * * *}$ & $0.08 * * *$ & $0.04 * *$ & $0.01 \mathrm{n} . \mathrm{s}$. & $0.14 * * *$ & 0.00 n.s. & $0.08 * * *$ & 0.00 n.s. & $0.11 * * *$ \\
\hline & Large & $\mathrm{N}=10,523$ & $0.03 *$ & -0.01 n.s. & $-0.15^{* * *}$ & $0.09^{* * *}$ & 0.00 n.s. & $-0.17 * * *$ & $0.13^{* * *}$ & $0.09^{* * * *}$ & $0.07^{* * * *}$ & $-0.08^{* * *}$ & 0.02 n.s. & $-0.08 * * *$ & $0.15^{* * * *}$ & $-0.04^{* * * *}$ & $-0.08 * * *$ & $0.06^{* * *}$ & $-0.05^{* * * *}$ \\
\hline \multirow{2}{*}{ Gend } & Female & $\mathrm{N}=8,723$ & $0.12 * * *$ & $0.12 * * *$ & $0.03 * *$ & $0.14 * * *$ & $0.07 * * *$ & 0.02 n.s. & $0.17 * * *$ & $0.09 * * *$ & $0.12 * * *$ & $0.10^{* * * *}$ & $0.07 * * *$ & $0.05 * * *$ & $0.20^{* * * *}$ & $0.04 * * *$ & $0.07 * * *$ & $0.04 * * *$ & $0.12 * * *$ \\
\hline & Male & $\mathrm{N}=6,656$ & $0.12 * * *$ & $0.14 * * *$ & $0.03 *$ & $0.17^{* * * *}$ & $0.10^{* * * *}$ & $0.06^{* * * *}$ & $0.15^{* * * *}$ & $0.13^{* * * *}$ & $0.16^{* * * *}$ & $0.10^{* * * *}$ & $0.10^{* * * *}$ & $0.07^{* * * *}$ & $0.19 * * *$ & $0.06 * * *$ & $0.08^{* * * *}$ & $0.09 * * *$ & $0.11^{* * * *}$ \\
\hline \multirow{3}{*}{ Age } & 30 or Ur & $\mathrm{N}=1,948$ & $0.10^{* * *}$ & $0.13^{* * *}$ & $-0.01 \mathrm{n} . \mathrm{s}$. & $0.19^{* * *}$ & $0.09^{* * *}$ & $0.08^{* *}$ & $0.21 * * *$ & $0.09^{* * *}$ & $0.20^{* * * *}$ & $0.09^{* * *}$ & $0.07 * *$ & $0.06^{* *}$ & $0.14 * * *$ & $0.06^{* *}$ & $0.04 \mathrm{n} . \mathrm{s}$. & $0.05^{*}$ & $0.10^{* * * *}$ \\
\hline & $31-50$ & $\mathrm{~N}=5,471$ & $1 * * *$ & $0.13 * * *$ & 0.01 n.s. & $0.14 * * *$ & $0.03 *$ & $0.05 * * *$ & $0.16^{* * *}$ & $0.07 * * *$ & $0.15^{* * *}$ & $0.08 * * *$ & $0.03 *$ & $0.06^{* * *}$ & $0.13 * * *$ & $0.06^{* * *}$ & $0.09^{* * *}$ & $0.04 * *$ & $0.11 * * *$ \\
\hline & Over 50 & $\mathrm{~N}=2,933$ & $0.10 * * *$ & $0.10 * * *$ & -0.03 n.s. & $0.16^{* * *}$ & $0.07 * * *$ & 0.02 n.s. & $0.16^{* * *}$ & $0.10 * * *$ & $0.14 * * *$ & $0.11 * * *$ & $0.05^{* * *}$ & $0.05^{* *}$ & $0.17 * * *$ & $0.07 * * *$ & $0.07^{* * *}$ & $0.07 * * *$ & $0.10^{* * *}$ \\
\hline \multirow{5}{*}{ Type of Work } & Administ & $\mathrm{N}=1,397$ & 0.01 n.s. & 0.00 n.s. & $-0.07 * *$ & $0.13^{* * *}$ & $-0.02 n . s$. & $-0.07 *$ & $0.15^{* * *}$ & -0.05 n.s. & $0.13^{* * *}$ & -0.03 n.s. & 0.01 n.s. & $\begin{array}{l}-0.02 n . s . \\
\end{array}$ & 0.00 n.s. & 0.00 n.s. & $-0.09 * *$ & -0.02 n.s. & -0.04 n.s. \\
\hline & Technical & $\mathrm{N}=1,357$ & $0.14 * * *$ & $0.14 * * *$ & $-0.07 * *$ & $0.31 * * *$ & 0.03 n.s. & $0.06^{*}$ & $0.32 * * *$ & $0.10^{* * *}$ & $0.30^{* * *}$ & -0.01 n.s. & $0.05 *$ & 0.02 n.s. & $0.12 * * *$ & $0.06^{*}$ & $0.06^{*}$ & 0.05 n.s. & -0.01 n.s. \\
\hline & Professional & $\mathrm{N}=2,997$ & $0.12 * * *$ & $0.12 * * *$ & $-0.04 *$ & $0.30^{* * * *}$ & $0.06 * *$ & -0.02 n.s. & $0.33^{* * * *}$ & $0.11^{* * * *}$ & $0.26^{* * * *}$ & $0.10^{* * * *}$ & $0.06^{* *}$ & 0.01 n.s. & $0.11 * * *$ & $0.08 * * *$ & $0.05^{* *}$ & $0.09 * * *$ & $0.02 \mathrm{n} . \mathrm{s}$. \\
\hline & Managerial/Supervision & $\mathrm{N}=1,078$ & $0.10^{* *}$ & $0.08 * *$ & $-0.07 *$ & $0.27 * * *$ & 0.02 n.s. & -0.02 n.s. & $0.29 * * *$ & 0.06 n.s. & $0.29 * * *$ & 0.06 n.s. & -0.04 n.s. & -0.05 n.s. & $0.11 * * *$ & -0.05 n.s. & $-0.06 *$ & 0.03 n.s. & -0.04 n.s. \\
\hline & Other & $\mathrm{N}=494$ & $0.13 * *$ & $0.14 * *$ & -0.07 n.s. & $0.35 * * *$ & 0.05 n.s. & 0.08 n.s. & $0.42 * * *$ & 0.08 n.s. & $0.33^{* * *}$ & 0.10n.s. & $0.14 * *$ & 0.05n.s. & $0.18 * * *$ & $0.10^{*}$ & 0.07n.s. & 0.06n.s. & $0.11 *$ \\
\hline \multirow{2}{*}{$\begin{array}{c}\text { Time at } \\
\text { Workspace }\end{array}$} & Less than 1 year & $\mathrm{N}=1,864$ & $0.22 * * *$ & $0.23 * * *$ & -0.03 n.s. & $0.31^{* * * *}$ & $0.12 * * *$ & 0.04 n.s. & $0.36^{* * * *}$ & $0.13^{* * * *}$ & $0.28^{* * * *}$ & $0.21^{* * *}$ & $0.10^{* * *}$ & $0.07 * *$ & $0.19 * * *$ & $0.26 * * *$ & $0.15^{* * * *}$ & $0.13^{* * *}$ & $0.18^{* * * *}$ \\
\hline & More than 1 year & $\mathrm{N}=3,859$ & $0.06 * * *$ & 0.03 n.s. & $-0.07 * * *$ & $0.28 * * *$ & -0.01 n.s. & $-0.05 * *$ & $0.29 * * *$ & 0.03 n.s. & $0.25^{* * *}$ & -0.01 n.s. & $0.01 \mathrm{n} . \mathrm{s}$. & $-0.04 *$ & $0.06 * * *$ & $-0.06^{* * *}$ & $-0.07 * * *$ & 0.02 n.s. & $-0.08^{* * *}$ \\
\hline \multirow{3}{*}{$\begin{array}{c}\text { Weekly Working } \\
\text { Hours }\end{array}$} & 10 or less & $\mathrm{N}=675$ & $0.12^{* *}$ & $0.16 * * *$ & -0.01 n.s. & $0.13^{* *}$ & $0.08^{*}$ & 0.04 n.s. & $0.13 * * *$ & $0.14 * * *$ & $0.11^{* *}$ & 0.06 n.s. & $0.09 *$ & $0.09 *$ & $0.23^{* * *}$ & 0.05 n.s. & $0.01 \mathrm{n} . \mathrm{s}$ & $0.09^{*}$ & 0.05 n.s. \\
\hline & $11-30$ & $\mathrm{~N}=3,360$ & $0.07 * * *$ & $0.07 * * *$ & -0.03 n.s. & $0.11^{* * *}$ & $0.05 * *$ & $-0.04^{*}$ & $0.11 * * *$ & $0.10 * * *$ & $0.11 * * *$ & $0.04 *$ & $0.05^{* *}$ & 0.02n.s. & $0.16^{* * * *}$ & -0.01 n.s. & $0.04 *$ & 0.03 n.s. & 0.02 n.s. \\
\hline & More than 30 & $\mathrm{~N}=14,380$ & $0.02 *$ & 0.01 n.s. & $-0.09 * * *$ & $0.05^{* * *}$ & 0.00 n.s. & $-0.11 * * *$ & $0.08 * * *$ & $0.07^{* * *}$ & $0.03^{* * *}$ & $-0.03 * * *$ & 0.01 n.s. & $-0.05 * * *$ & $0.13^{* * *}$ & $-0.04 * * *$ & $-0.04 * * *$ & 0.02 n.s. & -0.02 n.s. \\
\hline
\end{tabular}

$\mathrm{N}=$ number of responses

$* * * \mathrm{p}<0.001 ; * * \mathrm{p}<0.01 ; * \mathrm{p}<0.05 ; \mathrm{n} . \mathrm{s} .=$ not significant

Values in bold italic indicate a small effect size $(0.20 \leq$ rho $<0.50)$ 
Table 4. Absolute variation of mean vote of satisfaction $(\Delta \mathrm{V})$ with building, workspace and 15 IEQ parameters for each non-environmental factor

\begin{tabular}{|c|c|c|c|c|c|c|c|c|c|c|c|c|c|c|c|c|c|}
\hline & 泀 & 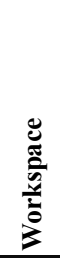 & 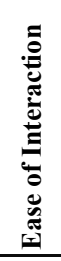 & 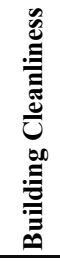 & 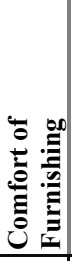 & 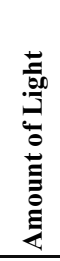 & 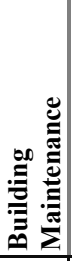 & 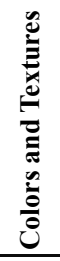 & 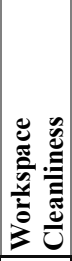 & 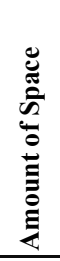 & 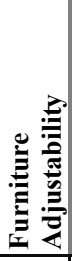 & 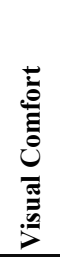 & 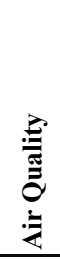 & 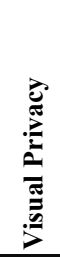 & $\begin{array}{l}\ddot{n} \\
\ddot{0} \\
z\end{array}$ & 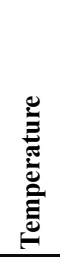 & 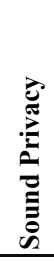 \\
\hline Office Type & 0.21 & 0.35 & 0.22 & 0.07 & 0.14 & 0.11 & 0.04 & 0.21 & 0.02 & 0.07 & 0.13 & 0.02 & 0.12 & 0.39 & 0.33 & 0.50 & 0.32 \\
\hline Spatial Layout & 0.68 & 0.86 & 0.40 & 0.50 & 0.54 & 0.97 & 0.51 & 0.48 & 0.61 & 0.81 & 0.54 & 0.44 & 0.33 & 1.15 & 0.94 & 0.60 & 0.87 \\
\hline Distance from Window & 0.01 & 0.01 & 0.03 & 0.15 & 0.03 & 0.00 & 0.14 & 0.06 & 0.16 & 0.07 & 0.04 & 0.03 & 0.10 & 0.07 & 0.07 & 0.11 & 0.26 \\
\hline Building size & 0.31 & 0.30 & 0.48 & 0.23 & 0.10 & 1.10 & 0.39 & 0.06 & 0.06 & 0.63 & 0.14 & 0.63 & 0.11 & 0.47 & 0.61 & 0.21 & 0.79 \\
\hline Gender & 0.01 & 0.08 & 0.03 & 0.05 & 0.08 & 0.08 & 0.05 & 0.08 & 0.04 & 0.02 & 0.09 & 0.04 & 0.10 & 0.06 & 0.02 & 0.18 & 0.01 \\
\hline Age & 0.04 & 0.07 & 0.14 & 0.11 & 0.17 & 0.25 & 0.13 & 0.07 & 0.18 & 0.10 & 0.13 & 0.08 & 0.14 & 0.01 & 0.19 & 0.08 & 0.08 \\
\hline Type of Work & 0.44 & 0.45 & 0.15 & 0.67 & 0.28 & 0.51 & 0.77 & 0.50 & 0.67 & 0.46 & 0.65 & 0.33 & 0.61 & 0.59 & 0.57 & 0.42 & 0.58 \\
\hline Time at Workspace & 0.47 & 0.58 & 0.10 & 0.03 & 0.39 & 0.26 & 0.05 & 0.30 & 0.04 & 0.73 & 0.32 & 0.33 & 0.39 & 1.25 & 0.83 & 0.41 & 1.05 \\
\hline Weekly Working Hours & 0.26 & 0.45 & 0.21 & 0.17 & 0.23 & 0.52 & 0.09 & 0.21 & 0.25 & 0.37 & 0.24 & 0.47 & 0.35 & 0.40 & 0.28 & 0.29 & 0.31 \\
\hline
\end{tabular}

Values in bold italic indicate an absolute variation of mean vote of satisfaction $(\Delta \mathrm{V})$ higher than 0.40

\section{DISCUSSION}

\subsection{Impact of non-environmental factors on occupant satisfaction}

The literature survey conducted by Frontczak and Wargocki [20] suggested that comfort and satisfaction can be influenced by factors "unrelated to environmental quality", such as features of the building and the workspace, personal characteristics of the occupants, and their work activities. However, their review showed inconsistent quantification of the impact of individual non-environmental variables on the overall users' IEQ satisfaction. In a previous work described in the Introduction [1], and based on the analysis of a subset of the CBE survey database, the authors concluded that - when users' responses are evaluated comprehensively - LEED certification does not bear a relevant influence on the satisfaction of occupants with the building, the workspace, and 15 parameters of indoor environmental quality. In the dataset analyzed, LEED and non-LEED certified buildings presented practically negligible differences in perceived occupant IEQ satisfaction. Therefore, in light of these results, the study described in this paper was set to investigate whether differences in occupant satisfaction of more practical relevance could be detected and quantified when looking at occupants' responses expressed under specific categorizations of factors unrelated to environmental quality.

A preliminary answer to this question is offered by the analysis of Table 2, which provides the difference in mean vote of satisfaction $(\Delta \mathrm{M})$ given by occupants of LEED and non-LEED buildings according to various categorizations of nine non-environmental factors. As mentioned, the data of Table 2 can help to find patterns of possible influence of variables unrelated to environmental quality on the alteration of occupant satisfaction votes. A potential tendency was reported in the Results section, leading to hypothesize a higher effectiveness of LEED certification in terms of satisfaction with building, workspace, noise, temperature, and sound privacy, in open rather than in enclosed offices. Another interesting pattern is represented by the nearly equipollent 'inversion' of satisfaction with some IEQ parameters between occupants of LEED and non-LEED buildings according to the variation of nonenvironmental factors. For example, in the case of visual privacy, occupants of enclosed offices expressed a higher satisfaction with this parameter in non-LEED buildings $(\Delta \mathrm{M}=-0.56)$, while users working in offices featured in the 'other' open layouts were more satisfied with visual privacy in buildings certified by LEED $(\Delta \mathrm{M}=+0.59)$. Similarly, occupants of LEED buildings of small size indicated to be more satisfied with amount of light $(\Delta \mathrm{M}=+0.37)$ than users of non-LEED buildings, whereas occupants of large size buildings expressed a higher satisfaction with this factor of indoor environmental quality in buildings not rated by LEED $(\Delta \mathrm{M}=-0.73)$. On the other hand, for some IEQ parameters, a variation in non-environmental factors does not lead to a different trend of satisfaction votes. For instance, occupants were consistently more satisfied with air quality and building maintenance in LEED-rated offices, regardless of non-environmental factors. These patterns seem to suggest that buildings certified by LEED can be more (or less) effective in providing a difference in satisfaction vote with specific IEQ parameters according to the variation of features of the building and the workplace, or changes in the personal 
characteristics of occupants or their work activities. However, in order to confirm these hypotheses, a statistical significance test must be performed and the effect size needs to be calculated.

From the analysis of Table 3, it can be noted that for most combinations (341 out of 459) of IEQ parameters and categorizations of non-environmental factors there is a statistically significant difference in mean vote of satisfaction between occupants of LEED and non-LEED buildings. From this, it could be inferred that non-environmental factors do have a significant influence on the variation in occupant satisfaction between LEED and non-LEED buildings. Nevertheless, the effect size (practical difference, Spearman Rho, $\rho)$ is negligible $(\rho<0.20)$ for most variations $(314$ out of 341$)$. For 27 cases out of 341 , the effect size is small $(0.20 \leq \rho<0.50)$ and for none it is moderate $(0.50 \leq \rho<0.80)$ or strong $(0.80 \leq \rho$ $\leq 1)$. Therefore, the results of Table 3 lead to conclude that, in general, office type, spatial layout, distance from window, building size, gender, age, and weekly working hours, have practically no relevant influence in driving a variation in satisfaction with the building, workspace, and most of the indoor environmental quality parameters here considered between LEED and non-LEED certified buildings. Conversely, the non-environmental factors related to time at the workspace and, to some extent, type of work present small - yet, practically significant - effect sizes for differences in mean vote of satisfaction with the building, workspace, and several IEQ parameters (for example, building cleanliness, building maintenance, workspace cleanliness, etc.).

Finally, Table 4 indicates the absolute variation $(\Delta V)$ of mean satisfaction votes expressed by occupants of LEED and non-LEED buildings according to the diverse non-environmental factors considered. Table 4 can be useful to suggest the potential 'weight' that each variable unrelated to environmental quality can have in influencing differences in occupant satisfaction in LEED and nonLEED certified buildings. On the basis of the results presented in Table 4, the most interesting 'spread' of satisfaction votes can be found for spatial layout, building size, and time at the workspace. The first two factors can be directly affected by designers and building owners. Other considerable influences of nonenvironmental factors on the absolute variation of mean votes of satisfaction are noted for type of work and weekly working hours (however, it must be considered that the type of work is often linked with the office type and layout that users are provided with, and their work schedule). A detailed analysis and discussion of the influence of individual non-environmental factors on the variation of occupants' mean vote of satisfaction in LEED and non-LEED certified buildings is given in the sections below. To contextualize the findings, Figures 1 and 2 present the mean, median, first and third quartile (left), the differences in mean values between LEED and non-LEED buildings (center), and the effect size (right) of occupant satisfaction votes with the building (Figure 1) and the workspace (Figure 2) for four nonenvironmental factors (office type, spatial layout, building size, and time at workspace).
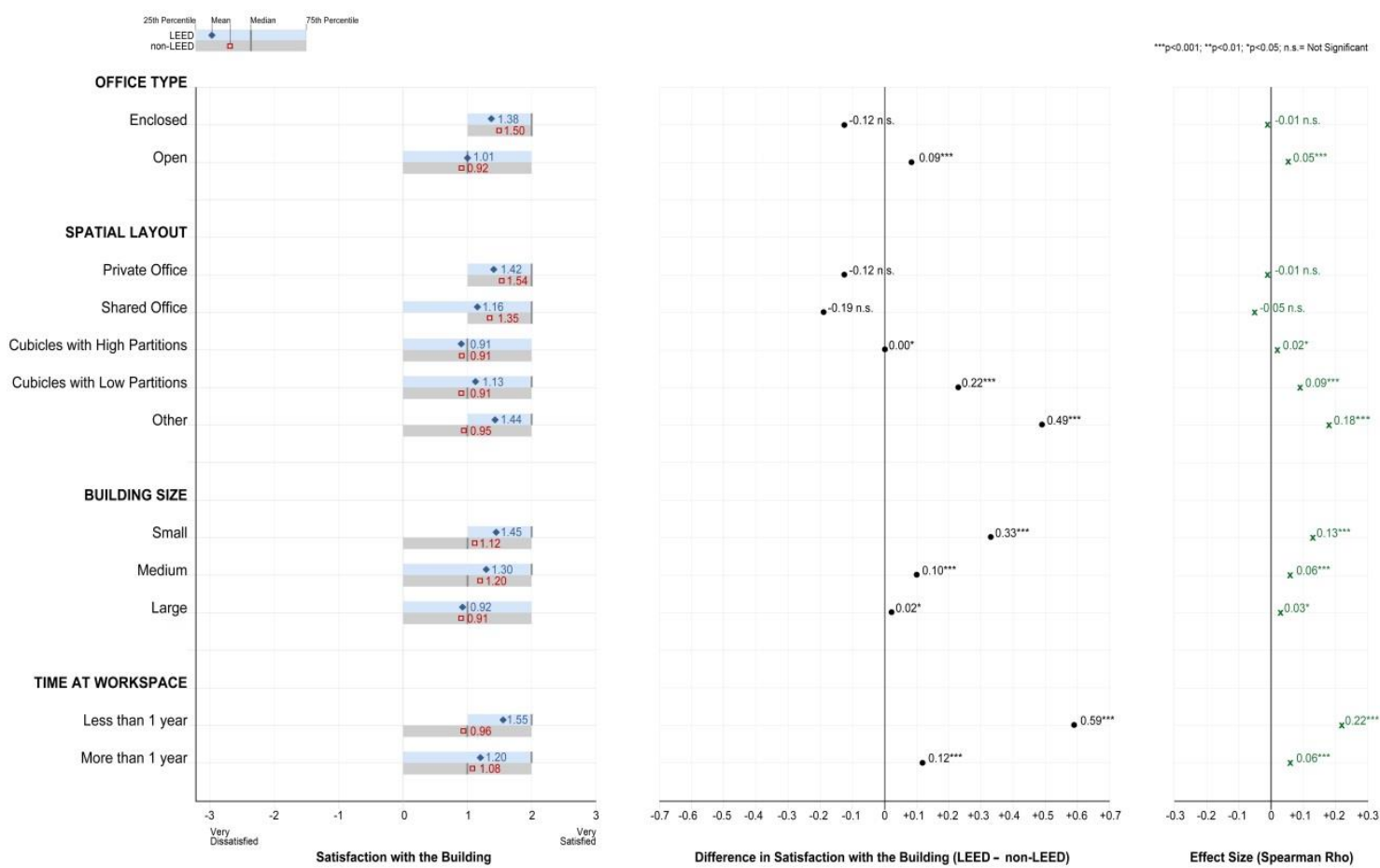

Figure 1. Mean, median, first and third quartile (left); Differences in mean values (LEED - non-LEED) (center); Effect size (Spearman Rho) (right) of occupant satisfaction with the building for four non-environmental factors (office type, spatial layout, building size and time at workspace). 

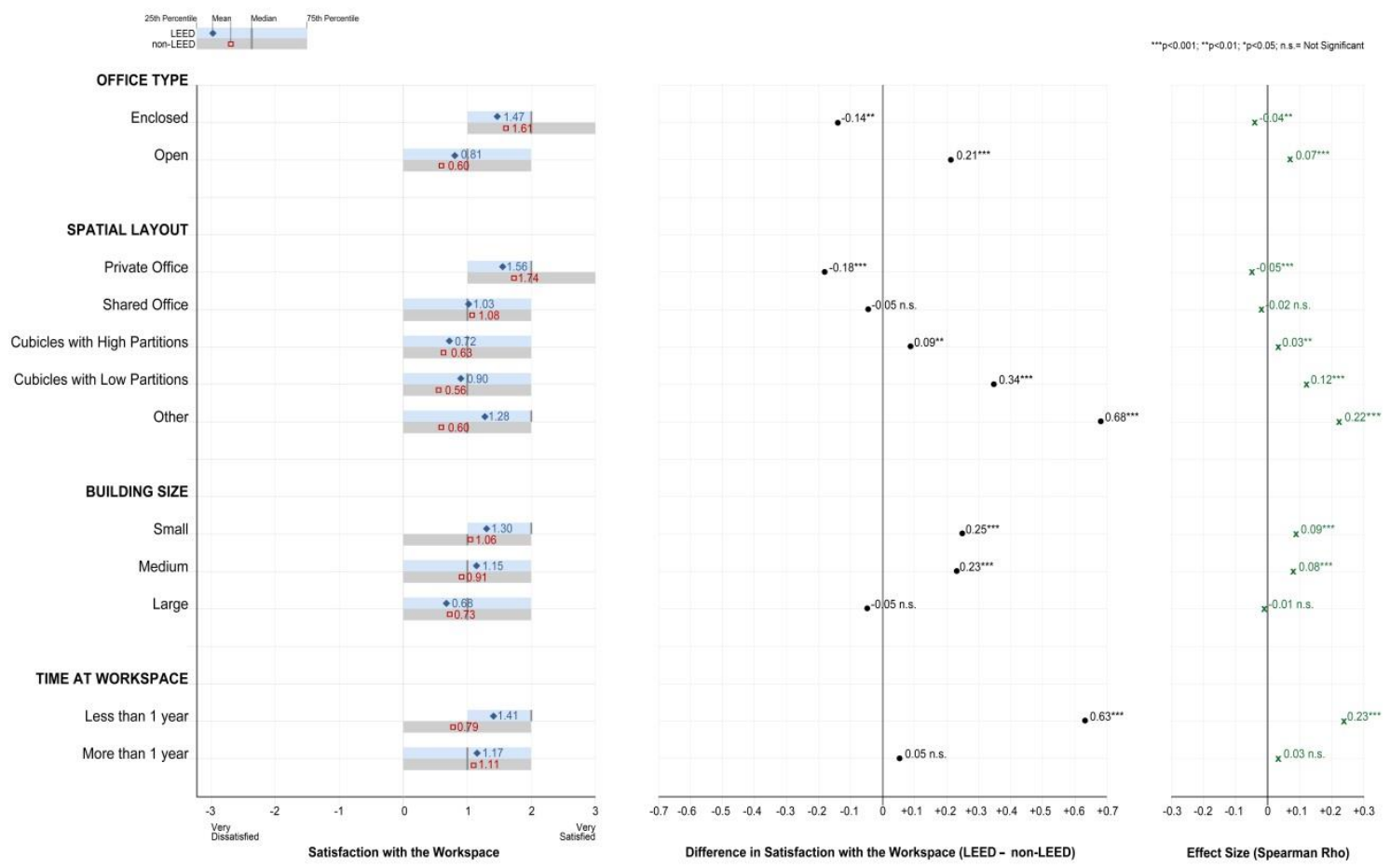

Figure 2. Mean, median, first and third quartile (left); Differences in mean values (LEED - non-LEED) (center); Effect size (Spearman Rho) (right) of occupant satisfaction with the workspace for four non-environmental factors (office type, spatial layout, building size and time at workspace).

\subsubsection{Office type}

Table 2 shows that for satisfaction with the building, the workspace, and most other parameters of indoor environmental quality, LEED certified buildings may be more 'effective' in open spaces rather than in enclosed offices, as indicated by a higher mean vote of occupant satisfaction under this categorization of office type (positive $\Delta \mathrm{M}$ ). Table 3 shows that the differences are mostly statistically significant (27 out of 34 ), but that the effect size is negligible for all the combinations of IEQ parameters and types of offices $(\rho<0.20)$.

According to Table 4, consideration of office types provides an absolute variation of the mean vote of satisfaction between occupants of LEED and non-LEED buildings higher than 0.40 only for satisfaction with temperature $(\Delta \mathrm{V}=0.50)$. The difference in mean votes of satisfaction with temperature between LEED and non-LEED buildings is, both in enclosed offices (LEED: $M=0.13$; non-LEED: $M=$ $0.48 ; \Delta \mathrm{M}=-0.35 ; \mathrm{p}<0.001 ; \rho=-0.09$ (negligible)) and in open spaces (LEED: $\mathrm{M}=-0.17$; non-LEED: $\mathrm{M}=$ $-0.32 ; \Delta \mathrm{M}=+0.15 ; \mathrm{p}<0.001 ; \rho=0.04$ (negligible)), statistically significant but with negligible effect size. Therefore, it can be concluded that based on the dataset analyzed, the office type does not have a practical influence on the difference in mean satisfaction of occupants with the building, workspace, and indoor environmental quality between LEED and non-LEED certified buildings.

However, it must be noted that the mean votes of occupant satisfaction with the building (Figure 1) and with the workspace (Figure 2) - as well as with the other 15 IEQ parameters featured in the CBE survey database - are always higher in enclosed offices than in open spaces for both LEED and nonLEED certified buildings. These results are in line with the conclusions of [13] that detected in private offices a significantly higher satisfaction with the amount of space - which was found to be the most predictive factor of satisfaction with the workspace. Satisfaction with most other IEQ parameters was also significantly higher in private and shared offices than in cubicles with high, low, or no partitions [13]. This is broadly in line with our findings and also consistent with the results reported in [17, 30, 31].

\subsubsection{Spatial layout}

According to Table 4, the spatial layout has a substantial influence on the absolute variation of mean satisfaction votes between LEED and non-LEED buildings $(\Delta \mathrm{V})$. As per Table 2, the mean satisfaction vote expressed by occupants of private offices is higher in non-LEED buildings (that is, negative $\Delta \mathrm{M})$ for all the parameters of indoor environmental quality considered with the exception of building cleanliness $(\Delta \mathrm{M}=+0.20 ; \mathrm{p}<0.001 ; \rho=0.12$ (negligible)), building maintenance $(\Delta \mathrm{M}=+0.31 ; \mathrm{p}<$ $0.001 ; \rho=0.13$ (negligible)), colors and textures $(\Delta \mathrm{M}=+0.03 ; \mathrm{p} \geq 0.05 ; \rho=0.03$ (negligible)), workspace 
cleanliness $(\Delta \mathrm{M}=+0.18 ; \mathrm{p}<0.001 ; \rho=0.07$ (negligible)) and air quality $(\Delta \mathrm{M}=+0.34 ; \mathrm{p}<0.001 ; \rho=0.12$ (negligible)), for which occupants of private offices expressed a higher satisfaction in LEED-rated buildings. Conversely, occupants of offices arranged in open layouts with high, low, or no partitions were almost invariably more satisfied with parameters of indoor environmental quality in LEED buildings, with only few exceptions. This pattern is clearly identifiable in Figure 1 and Figure 2 for satisfaction with the building and with the workspace, where a trend of increasing difference in satisfaction between LEED and non-LEED buildings (LEED minus non-LEED) is evident when moving from private offices to open spaces. These results could lead to assume that LEED rating may be more successful in improving occupant satisfaction in open spaces rather than in private and shared offices, although - even if mostly statistically significant - the effect size of the differences for almost all associations between spatial layouts and occupant satisfaction with parameters of indoor environmental quality is practically negligible. This assumption is however supported by the higher satisfaction with the workspace expressed by occupants of LEED buildings in open spaces featured within the 'other' category (e.g., open office layouts with limited or no partitions, cubicles with partitions of different heights, group work areas, etc.), which is characterized by both statistical significance and a practically relevant effect size $(\Delta \mathrm{M}=+0.68$; $\mathrm{p}<0.001 ; \rho=0.22$ (small)).

\subsubsection{Distance from window}

According to Table 4, the distance of the space of work from the window does not entail a substantial variation in occupant satisfaction with the building, workspace, and indoor environmental quality parameters between LEED and non-LEED certified buildings (in fact, the absolute variation of mean votes of satisfaction $\Delta \mathrm{V}$ is always lower than 0.26 ). This indicates that the satisfaction votes expressed by occupants in LEED and non-LEED buildings follow the overall trend of mean satisfaction calculated over the total sample of responses, irrespective of whether the workstation is located within 4.6 meters (15 feet) or further away from the window.

\subsubsection{Building size}

Table 4 suggests that building size has a relevant influence on the absolute variation of mean vote of satisfaction in LEED and non-LEED buildings, in particular for satisfaction with amount of light $(\Delta \mathrm{V}=1.10)$, sound privacy $(\Delta \mathrm{V}=0.79)$, amount of space $(\Delta \mathrm{V}=0.63)$, visual comfort $(\Delta \mathrm{V}=0.63)$, ease of interaction $(\Delta \mathrm{V}=0.48)$, and visual privacy $(\Delta \mathrm{V}=0.47)$. It is interesting to note that such parameters of indoor environmental quality are among those that can be most directly influenced by the design criteria that characterize the process of accreditation for the attainment of the LEED certification.

The data of Table 2 lead to infer that, at a general level, LEED-rated commercial office spaces may be more effective in delivering higher occupant satisfaction in small (size lower than $4,645 \mathrm{~m}^{2}$ or $50,000 \mathrm{gsf}$ ) rather than in large buildings (size higher than $18,580 \mathrm{~m}^{2}$ or $200,000 \mathrm{gsf}$ ). Occupants of LEED buildings of small size, in fact, indicated a higher mean vote of satisfaction with all the IEQ parameters considered, with the exception of satisfaction with ease of interaction, visual privacy, noise, and sound privacy. Conversely, occupants of non-LEED certified buildings of large size expressed a higher mean satisfaction vote with workspace, ease of interaction, amount of light, amount of space, visual comfort, visual privacy, noise, and sound privacy. In support of this inference, Figures 1 and 2 emphasize a tendency of decreasing difference (LEED minus non-LEED) in mean vote of occupant satisfaction with the building and with the workspace when moving from small to large buildings. Nevertheless, as per Table 3 (and Figures 1 and 2), although the relationships are statistically significant for most of the combinations analyzed between satisfaction with IEQ parameters and building sizes (42 out of 51), the differences have invariably a practically negligible effect size (always $\rho<0.20$ ).

The hypothesis that LEED rating may provide higher occupant satisfaction in small buildings is however consistent with the work of Leaman and Bordass [4], who indicated that smaller green buildings are often more successful than larger ones particularly since, for buildings of large size, it becomes much harder to resolve conflicting requirements towards satisfaction of users with, for example, lighting, noise, and the use of deep spaces. Also, in his studies on the comparison of energy performance data for LEED and non-LEED certified buildings of the same type, Scofield had concluded that the design strategies aimed at the obtainment of LEED certification are often more successful in small 'trophy' buildings, where they can have a measurable impact and their cost can be more easily justified and leveraged [32, 33].

\subsubsection{Gender and age}

As per Table 4, gender does not considerably affect the absolute variation of occupant satisfaction in LEED and non-LEED buildings ( $\triangle \mathrm{V}$ always lower than 0.18$)$. Of note, however, that votes 
given by males tend to express a slightly higher mean satisfaction than females with all IEQ parameters in both LEED and non-LEED buildings. In particular, in the case of satisfaction with temperature, the mean votes of satisfaction of males were always positive (LEED: $M=0.52$; non-LEED: $M=0.19 ; \Delta M=+0.33$; $\mathrm{p}<0.001 ; \rho=0.09$ (negligible)), while satisfaction with temperature expressed by females was constantly on the negative side of the scale (LEED: $M=-0.22$; non-LEED: $M=-0.36 ; \Delta M=+0.15 ; p<0.001 ; \rho=0.04$ (negligible)). Although almost all correlations have a practically negligible effect size, this indication is in line with the literature survey presented in [20], which revealed that men and women may, on some occasions, rank environmental conditions differently. Likewise, the study by Kim et al. [18] concluded that - regardless of equal overall workspace satisfaction ratings - female office workers are significantly more likely to complain about IEQ factors than their male counterparts.

The non-environmental factor of age does not substantially influence the vote of satisfaction in LEED and non-LEED buildings, as indicated by an absolute variation $\Delta \mathrm{V}$ always lower than 0.25 (Table 4). Across the relationships considered between occupant satisfaction with IEQ parameters and age groups, the only differences that have statistical significance and small effect size are related to a higher mean vote of satisfaction expressed by occupants of LEED buildings featured in the categorization of ' 30 or under' with building maintenance $(\Delta \mathrm{M}=+0.55 ; \mathrm{p}<0.001 ; \rho=0.21$ (small)) and with workspace cleanliness $(\Delta M=+0.60 ; p<0.001 ; \rho=0.20$ (small)).

In interpreting these outcomes, it is however important to emphasize that a large number of responses - 28\% for gender (6,098 total responses; 5,601 in LEED and 497 in non-LEED buildings) and $52 \%$ for age (11,125 total responses; 5,610 in LEED and 5,515 in non-LEED buildings) - did not include details on the personal characteristics of occupants (Table 1). Hence, these findings need to be treated with caution.

On the whole, it can be concluded that age and gender do not affect in a consistent way the difference in vote of satisfaction with indoor environmental quality between LEED and non-LEED certified buildings. These results are in line with the review presented in [20], which suggested that most individual characteristics of occupants, including age and gender, cannot be dependably correlated with overall IEQ occupant satisfaction.

\subsubsection{Type of work}

According to Table 4, consideration of type of work entails substantial variations (i.e., $\Delta \mathrm{V}$ larger than 0.40 ) of mean vote of IEQ satisfaction in LEED and non-LEED buildings for all parameters considered, apart from satisfaction with ease of interaction, comfort of furnishing, and visual comfort. Based on Table 3, however, most of the differences are statistically significant (51 out of 85) but with a negligible effect size. The only exceptions are represented by satisfaction with building cleanliness, building maintenance, and workspace cleanliness, that present, across most categorizations of work types, not only statistical significance, but also a practically relevant small effect size. For all these IEQ parameters, the mean vote of occupant satisfaction is consistently higher in LEED buildings.

Nevertheless, there are three important limitations to these results: 1) the type of work may be directly linked to spatial layouts - for example, users engaged with managerial tasks may more often occupy private offices - which, as noted previously, can influence occupant satisfaction; 2) in the CBE survey, the indication of type of work is self-assessed by respondents basing on their view of their main work activities; and, 3) only 33\% (7,313 individual responses; 4,722 in LEED and 2,601 in non-LEED buildings) of the responses available in the dataset were associated with a type of work.

\subsubsection{Time at workspace}

Consideration of time spent at the current workspace reveals a variation $\Delta \mathrm{V}$ in the mean vote of occupant satisfaction equal or higher than 0.40 between LEED and non-LEED buildings for seven parameters of indoor environmental quality (Table 4). Occupants of LEED buildings having spent less than one year at their current space of work expressed a mean vote higher than users of non-LEED buildings for satisfaction with the building $(\Delta \mathrm{M}=+0.59)$, the workspace $(\Delta \mathrm{M}=+0.63)$, and all other indoor environmental quality parameters with the exception of satisfaction with ease of interaction (Table 2). On the other hand, the effectiveness of LEED certification in providing a higher users' satisfaction with the building and with the workspace is less marked for longer times of occupation (respectively, $\Delta \mathrm{M}=+0.12$ and $\Delta \mathrm{M}=+0.05$ ). For most of the combinations considered under the categorization of 'less than one year' at the current workspace (11 out of 17), the difference in mean vote of satisfaction $(\Delta \mathrm{M})$ is higher than +0.40 , indicating occupants largely more satisfied with the building, workspace, and several IEQ parameters in LEED buildings (Table 2). The differences in mean votes of satisfaction are both statistically significant $(p<0.05)$ and with a practically relevant effect size $(\rho \geq 0.20)$ for 7 out of the 17 combinations analyzed under this categorization (Table 3). Figures 1 and 2 emphasize the difference in 
satisfaction with the building and with the workspace in LEED and non-LEED certified buildings according to the variation of the time that occupants have spent at their current space of work. From the data, it can be concluded that LEED-rated buildings may be more effective in providing higher satisfaction to users that have spent less than one year at their workspace rather than to those having occupied their place of work for a longer time.

These results are in line with the suggestions of Singh et al. [2], who stated that there can be an improvement in satisfaction with perceived indoor environmental quality and self-assessed productivity after the move into a new LEED-rated workspace, possibly as a result of employees' excitement about their new place of work (to note that $76 \%$ of responses in our dataset were obtained in buildings certified by LEED for New Constructions). In this context, the 'Hawthorne effect' [34, 35] - although disputed by some studies [36] - has been linked to a temporary bias in occupants' perception of their performance and satisfaction resulting from a change in the work environment. Based on our findings, there are evidences that the positive value of LEED certification on occupant satisfaction may tend to diminish with the time spent at the space of work. Further studies on the robustness of the benefit of LEED certification in time from the point of view of the users would be much useful.

From the data presented in Tables 2 and 3, it should also be noted that occupants of LEED buildings expressed a higher satisfaction with the IEQ parameters of building cleanliness, building maintenance, and workspace cleanliness irrespective of the time spent at their current space of work. For all these relationships, practically relevant statistical significance was found in the differences in mean vote of satisfaction between LEED and non-LEED buildings. This confirms that the design criteria and credits that lead to LEED certification may be effective in providing the perception of a cleaner working environment to occupants.

These results need, however, to be treated with caution considering that for $73 \%$ of responses in the dataset analyzed (15,754 responses; 6,093 in LEED and 9,661 in non-LEED buildings) no information was available about the time that occupants have spent at their current workspace.

\subsubsection{Weekly working hours}

The number of hours spent per week at the place of work influences the absolute difference in mean vote of occupants' satisfaction in LEED and non-LEED buildings by a range equal or larger than $\Delta \mathrm{V}=0.40$ for satisfaction with amount of light $(\Delta \mathrm{V}=0.52)$, visual comfort $(\Delta \mathrm{V}=0.47)$, workspace $(\Delta \mathrm{V}=$ $0.45)$, and visual privacy $(\Delta \mathrm{V}=0.40)$ (Table 4$)$. Based on the data of Table 2 , for all these parameters a higher mean vote of satisfaction was expressed in LEED buildings by occupants spending 10 or less hours per week at their workplace, while - apart from satisfaction with the workspace - occupants of nonLEED buildings gave a higher mean vote of satisfaction with these parameters when occupying their place of work for more than 30 weekly hours. Table 3, however, indicates that the relationships between satisfaction with these IEQ factors and categorizations of weekly working hours are not always statistically significant (for 5 out of 12 combinations, $\mathrm{p} \geq 0.05$ ) and that the effect size is negligible in all cases.

Occupants spending less than 10 hours per week at their place of work are considerably more satisfied with air quality in LEED buildings $(\Delta \mathrm{M}=+0.80)$. This difference is both statistically significant and practically relevant $(\mathrm{p}<0.001 ; \rho=0.23$ (small)). A higher satisfaction with air quality in LEED buildings is also detected for other working schedules, but the 'gap' in mean votes of satisfaction between LEED and non-LEED buildings decreases with the increase of weekly hours of work. This suggests that LEED may reduce its effectiveness in providing satisfaction with IAQ the more time is spent at the place of work. However, this assumption is not fully supported by Table 3, since all the differences between satisfaction with air quality and weekly working hours are statistically significant but the effect size is negligible for occupants spending 11-30 hours $(\Delta \mathrm{M}=+0.51, \mathrm{p}<0.001 ; \rho=0.16)$ and more than 30 hours $(\Delta \mathrm{M}=+0.45, \mathrm{p}<0.001 ; \rho=0.13)$ per week at their workplace.

\subsection{Limitations of the study}

The same limitations described in Paragraph 4.3 of [1] are applicable to this work.

Among these, contrary to other studies such as those of Newsham et al. [37,38], a limit in the analysis of the data featured in the CBE survey database consists in the fact that the collection of occupants' responses is not related to physical measurements of the building and the workspace. Also, other parameters not included in the CBE survey may have a significant influence on the IEQ satisfaction of building users. In addition, the selection of buildings included in the database is not based on a systematic randomized approach, and the majority of the responses were obtained from buildings situated in the US (83\%). 
A further limitation is represented by the fact that the dataset considered for this analysis is only partially representative of the total amount of buildings that have been certified by the LEED rating system to date, although this shortcoming is explicable if related to the exponential growth in popularity of the LEED program, both in the US and internationally. However, it must be considered that - up until version v4 - the distribution of credits under the category of Indoor Environmental Quality has remained largely unchanged in the most recent versions of the various LEED products, although clearly the requirements for the award of credits have been progressively specified and detailed.

A final limitation of this study is represented by the fact that no analysis has yet been performed, for each of the LEED buildings included in our dataset, on the potential correlation between satisfaction of occupants and: 1) the level of LEED rating obtained by the buildings (e.g., Platinum, Gold, etc.); 2) the LEED version of the product under which the certification has been achieved; and, 3) the LEED scorecards providing the allocation of credits that each of the LEED buildings featured in our dataset has been awarded under the Indoor Environmental Quality category. Study of these relationships and potential additional investigations - e.g. consideration of self-estimated job satisfaction and productivity will be part of further research.

\section{CONCLUSIONS}

The analysis presented in this paper leads to conclude that several factors unrelated to environmental quality statistically significantly influence the difference in occupant satisfaction between LEED and non-LEED certified buildings, but the effect size of such variations is, for most, practically negligible. Therefore, based also on the results presented by the authors in [1], it can be concluded that occupants of LEED-rated buildings have equal satisfaction with the building, the workspace, and various parameters of indoor environmental quality than users of non-LEED certified buildings independently of office type, spatial layout, distance from window, building size, gender, age, type of work, and weekly working hours.

Conversely, consideration of time spent at the workspace (less or more than one year) presents statistically significant and practically relevant differences in occupant satisfaction with the building, the workspace, and several other IEQ parameters, for which occupants of LEED buildings tend to be more satisfied. The results obtained suggest that the positive value of LEED certification from the point of view of the satisfaction of occupants may tend to decrease with time.

The other main conclusions that can be drawn from the study described in this paper are:

- $\quad$ Occupant satisfaction with the workspace is higher in LEED buildings for users of open spaces with limited or no partitions, or with group work areas. Statistically significant differences in satisfaction with other IEQ parameters also suggest that LEED-rated buildings may be more effective in providing occupant satisfaction in open spaces rather than in enclosed offices, although the effect size for most of these variations is practically negligible.

- LEED-rated office spaces may be more effective in delivering occupant satisfaction in small rather than in large buildings, even if most of the statistically significant differences detected do not have a practically relevant effect size.

- The number of 'not available' responses in the categories related to age, gender, type of work, and time at workspace seems to suggest reluctance from building occupants to provide personal information when asked to report on their satisfaction with the environmental quality of their place of work.

\section{ACKNOWLEDGMENTS}

This research was supported by the HEA-Higher Education Academy, International Scholarship Scheme (United Kingdom), and by the CBE-Center for the Built Environment, University of California Berkeley (United States). The authors would like to thank Gail Brager and Ed Arens for their valuables advices and Monika Frontczak for the development of the dataset in R.

\section{REFERENCES}

[1] Altomonte S, Schiavon S. Occupant satisfaction in LEED and non-LEED certified buildings. Building and Environment 2013;68:66-76.

[2] Singh A, Syal M, Grady SC, Korkmaz S. Effects of Green Buildings on Employee Health and Productivity. American Journal of Public Health 2010;100:1665-8.

[3] Baird G, Leaman A, Thompson J. A comparison of the performance of sustainable buildings with conventional buildings from the point of view of the users. Architectural Science Review 2012;55:135-44. 
[4] Leaman AJ, Bordass WT. Are users more tolerant of 'green' buildings? Building Research and Information 2007;35:662-73.

[5] Liang H, Chen C, Hwang R, Shih W, Lo S, Liao H. Satisfaction of occupants toward indoor environment quality of certified green office buildings in Taiwan. Building and Environment 2014;72:232-42.

[6] Huizenga C, Laeser K, Arens EA. A Web-Based Occupant Satisfaction Survey for Benchmarking Building Quality. Proceedings of Indoor Air, Monterey, CA 2002.

[7] Zagreus L, Huizenga C, Arens EA, Lehrer D. Listening to the occupants: a Web-based indoor environmental quality survey. Indoor Air 2004;14 (Suppl. 8):65-74.

[8] Huizenga C, Abbaszadeh S, Zagreus L, Arens EA. Air quality and thermal comfort in office buildings: results of a large indoor environmental quality survey. Proceedings of Healthy Buildings 2006;III:393-7.

[9] Abbaszadeh S, Zagreus L, Lehrer D, Huizenga C. Occupant Satisfaction with Indoor Environmental Quality in Green Buildings. Proceedings of Healthy Buildings 2006;III:365-70.

[10] Brager GS, Baker L. Occupant Satisfaction in Mixed-Mode Buildings. Proceedings of Air Conditioning and the Low Carbon Cooling Challenge Windsor, UK 2008.

[11] Lee YS, Kim S. Indoor Environmental Quality in LEED-Certified Buildings in the US. Journal of Asian Architecture and Building Engineering 2008;7:293-300.

[12] Lee YS, Guerin DA. Indoor Environmental Quality Related to Occupant Satisfaction and Performance in LEED-certified Buildings. Indoor and Built Environment 2009;18:293-300.

[13] Frontczak M, Schiavon S, Goins J, Arens EA, Zhang H, Wargocki P. Quantitative relationships between occupant satisfaction and satisfaction aspects of indoor environmental quality and building design. Indoor Air 2012;22:119-31.

[14] Kim J, de Dear RJ. Nonlinear relationships between individual IEQ factors and overall workspace satisfaction. Building and Environment 2012;49:33-40.

[15] Lee YS, Guerin DA. Indoor environmental quality differences between office types in LEED-certified buildings in the US. Building and Environment 2010;45:1104-12.

[16] Lee YS. Office layout affecting privacy, interaction, and acoustic quality in LEED-certified buildings. Building and Environment 2010;45:1594-600.

[17] Kim J, de Dear RJ. Workspace satisfaction: The privacy-communication trade-off in openplan offices. Journal of Environmental Psychology 2013;36:18-26.

[18] Kim J, de Dear R, Candido C, Zhang H, Arens E. Gender differences in office occupant perception of indoor environmental quality (IEQ). Building and Environment 2013;70:245-56.

[19] Wargocki P, Frontczak M, Schiavon S, Goins J, Arens EA, Zhang H. Satisfaction and selfestimated performance in relation to indoor environmental parameters and building features. Proceedings of 10th International Conference on Healthy Buildings 2012.

[20] Frontczak M, Wargocki P. Literature survey on how different factors influence human comfort in indoor environments. Building and Environment 2011;46:922-37.

[21] Siegel S. Nonparametric statistics for the behavioral sciences. 1956.

[22] Cohen J. Statistical power analysis for the behavioral sciences. : Lawrence Erlbaum, 1988.

[23] Cohen J. The earth is round ( $\mathrm{p}<.05$ ). American Psychologist 1994;49:997-1003.

[24] Field AP, Hole G. How to design and report experiments. London: Sage, 2003.

[25] Cohen J. A power primer. Psychological Bulletin 1992;112:155.

[26] Ferguson CJ. An effect size primer: A guide for clinicians and researchers. Professional Psychology: Research and Practice 2009;40:532.

[27] Coe R. Effect size. In: Arthur J, Waring M, Coe R, Hedges LV, editors. Research Methods and Methodologies in Education, London: Sage; 2012, p. 368-377.

[28] Ellis PD. The Essential Guide to Effect Sizes. Statistical Power, Meta-Analysis, and the Interpretation of Research Results. Cambridge: Cambridge University Press, 2010.

[29] R Development Core Team. R: A language and environment for statistical computing. 2013; R version 3.0.2.

[30] Brennan A, Chugh JS, Kline T. Traditional versus open office design: A longitudinal field study. Environment and Behaviour 2002;34:279-99.

[31] Marans RW, Spreckelmeyer KF. Evaluating open and conventional office design. Environment and Behaviour 1982;14:333-51.

[32] Scofield JH. Do LEED-certified buildings save energy? Not really... Energy and Buildings 2009;41:1386-90. 
[33] Scofield JH. Efficacy of LEED-certification in reducing energy consumption and greenhouse gas emission for large New York City office buildings $<$ br $/>$. Energy and Buildings 2013;67:517-24.

[34] Franke RH, Kaul JD. The Hawthorne experiments: First statistical interpretation. American Sociology Review 1978;43:623-43.

[35] McCarney R, Warner J, Iliffe S, van Haselen R, Griffin M, Fisher P. The Hawthorne Effect: a randomised, controlled trial. BMC Medical Research Methodology 2007;7:30.

[36] Adair JG. The Hawthorne effect: A reconsideration of the methodological artifact. Journal of Applied Psychology 1984;69(2):334-45.

[37] Newsham G, Birt B, Arsenault C, Thompson L, Veitch J, Mancini S et al. Do Green Buildings Outperform Conventional Buildings? Indoor Environment and Energy Performance in North American Offices. National Research Council Canada 2012;RR-329:1-71.

[38] Newsham GR, Birt B, J., Arsenault C, Thompson A, Veitch J, Mancini S et al. Do 'green' buildings have better indoor environments? New evidence. Building Research \& Information 2013;41:4:415-34. 